although that of a thin pale woman of a type extremely convenient for abdominal palpation, was so firm that the examining hand gained little information as to what might be beneath the muscle. Gas and ether were well taken but when ether anæsthesia was fully established there was still firm resistance in the upper part of the left rectus muscle. Operation was decided upon and was performed a few days later. On this occasion, after gas and ether, the patient was brought deeply under the influence of chloroform. The contracted state of the left rectus muscle was uninfluenced. The operation exposed a chronic ulcer on the anterior wall of the stomach with dense adhesion to the under surface of the abdominal wall. It is quite possible that a similar condition of the abdominal wall might occur in a case of chronic appendicitis. In muscular subjects much inconvenience would thus probably be caused, although as a general rule operations on the lower parts of the abdomen, particularly towards the side, are much less interfered with by muscular conditions than those above the umbilicus.

In the case just related there was organic alteration of the muscle, or else a permanent institution of that protective contraction which is so obvious over an acute peritoneal lesion, and which is usually so entirely relieved when the patient is anæsthetised. The contraction is, of course, in the acute cases a reflex phenomenon and is therefore generally abolished, like other reflexes, by deep anæsthesix. Similar instances have lately been described by Sir William Bennett ${ }^{2}$ under the name "protective phantoms." When the contraction is met, as in the above instance, naturally the anæsthetist, and still more the surgeon, supposes that if not due to cyanosis or air obstruction it is merely due to too light an anæsthesia. I have satisfied myself that this is not so by pushing chloroform in such a case to the very limit of safety-to a point at which the pupil was dilated to more than three-quarter size and the breathing was beginning to fail-and then inquiring again of the surgeon as to the contracted condition of the muscle. It was as unsatisfactory as before. This state is happily not often seen. If it very seriously inconvenienced the surgeon the only remedy I imagine would be for him to divide the muscle across

A guide as to the causation and to the irremoveability or not of such contraction may come from noticing the condition of both sides of the abdomen. One side may be quite soft and convenient; the other, which shelters the disease, may be inconveniently firm, as in the gastric case I have related. Of course, the better the muscular development of the patient's abdomen the more inconvenience will these firm recti cause. A case in which they afforded the greatest trouble to the surgeon was that of a young soldier who, since an attack of enteric fever three years previously, had suffered from severe pain in the upper part of the abdomen. In him the contraction of the recti, which were very well developed, was not to be overcome by anæsthetics. Some firm adhesions about the transverse colon and stomach were divided and removed at the operation.

Taking, then, a general survey of the conditions of the abdominal wall which interfere with an operator's convenience, it may be seen that there are some unusual cases in which the anæsthetist cannot remove the difficulty, but that in the great majority of instances he can obtain a perfectly satisfactory condition by maintaining unimpeded breathing, complete absence of cyanosis, and sufficiently deep anæsthesia. These desiderata he obtains by properly selecting his anæsthetic, by giving it freely with a liberal air-supply, by keeping the air-passages free, and by holding the lower jaw well forward. When this is not enough the mouth must be slightly opened and the tongue drawn out One other point may be mentioned-viz., the element of time. It often happens that only towards the close of an operation is the patient's abdomen in a perfectly satisfactory condition from the surgeon's point of view. It is a good plan, therefore, in abdominal cases to let the anæsthetist get to work at the earliest po-sible moment-as soon, for in-tance, as the surgeon begins to get his instruments ready. By such a step a comfortable state may be insured throughout instead of at the close of the operation only the surgeon and anæ=thetist witressing the condition which they had all along been desiring.

Sloane-terrace Mansions, S.W.

\section{URETHRAL HAMORRHAGE IN GONORRHCEA.}

By J. F. DOBSON, M.S. Lond., F.R.C.S. ENG. LATE RESLENT SURGICAL OFFICER TO THE GENERAL INFIRMARY AT LEEDS.

THE following cases which have come under my care are of considerable interest and are good illustrations of a rare complication of gonorrhcea.

CASE 1.-A man, aged 26 years, attended at the Leeds General Infirmary on Sept. 2nd, 1899. He gave the following history. A month previously he had contracted gonorrhoea; the attack was of moderate severity and a profuse discharge persisted for a fortnight. It then diminished but never completely disappeared. He used an injection of potassium permanganate and also took capsules of santal oil by the mouth. There were no complications and beyond a little pain on micturition and a slight urethral discharge he was pertectly well on the morning of Sept. 2nd. On the evening of that day, after coitus, he immediately had a profuse hæmorrhage from the urethra. I saw him about half an hour afterwards. He had evidently lost a quantity of blood, his shirt and trousers being soaked; bright blood was issuing rapidly from the urethra. The hæmorrhage was arrested with some difficulty by the external application of ice and by injecting into the urethra a weak solution of tincture of hammamelis. He had a recurrence of the bleeding two days afterwards but it was not so profuse and was easily arrested. An injection of a 2 per cent. solution of protargol was ordered but this failed to cure the discharge, and after trying various remedies unsuccessfully I lost sight of him. The treatment adopted in this case wan not such as I should now recommend, but at that time I was ignorant of the use of the urethroscope.

CASE 2.-A miner, aged 17 years, attended at the Leeds General Infirmary on Feb. 26th, 1901. He was bleeding profusely from the urethra, so much so that he was brought in an ambulance. He had contracted gonorrhoea six weeks before and had had a urethral discharge ever since. The attack was of but moderate severity and was unattended by complications. He said that the bleeding had commenced when he was working in the pit. He had lost a quantity of blood and a stream of bright blood was proceeding from the meatus. The urethroscope tube was passed and the urethra was inspected. At first nothing could be seen owing to the bleeding, but after mopping the blood away with pieces of wool in holders and inflating the urethra with air it was seen that the hæmorrhage was proceeding from a congested granular-looking patch in the floor of the bulbous urethra. Bright blood was oozing rapidly from this patch. A -mall fragment of wool dipped in solution of perchloride of iron was applied to the direased area under the guirlance of the electric light. No other patches were discovered. The bleeding ceased at once on the application of the iron and the patient was sent home. There was no return of the hæmorrhage but there was some increase in the amount of discharge which was treated by the use of a $1 \frac{1}{2}$ per cent. protargol injection and at intervals by the application of a 10 per cent. solution of protargol to the disea-er portion of the urethra through the urethroscope. The discharge rapidly diminished under this treatment and the patient was discharged cured at the end of three weeks. The re-ult of the treatment adopted in this case was most striking and effective.

The next case is of a somewhat different nature to the preceding cases.

CASE 3.-A man, aged 24 years, seen on May 30th, 1901, had had acute gonorrhoea three months previously. The attack had been of considerable severity but there had been no complicatinns. He had a persistent dicharge and on several occasions there had been some bleeding from the urethra. This had never been very profuse hut was liable to come on after any particular exertion. He had taken various drugs by the mouth and had used a latge variety of injections; a metal sound had been passed on two ncca-ions. I saw him a few days after a smart attack of hæmorrhage. A muco-purulent discharge could be expres-ed from the urethra and this contained gonococci; there was no pain or difficulty in micturition but the meatus was extremely narrow. The meatus was incised, the urethroscope tube was 
passed, and the urethra was inflated with air. A congested papillary patch was found in the penile urethra, which bled readily on touching it with the probe. The remainder of the anterior urethra was apparently healthy and there was no evidence of a posterior urethritis. The diseased patch was swabbed with a 20 per cent solution of protargol through the urethroscope on three occasions at intervals of four or five days, the patient also using a $1 \frac{1}{2}$ per cent. injection of protargol night and morning. At the end of three weeks' treatment the discharge had ceased and there was no further hæmorrhage.

I have seen also two other cases of urethral hæmorrhage following gonorrhoea ; in both cases the bleeding was profuse and in one it was complicated by retention of urine. These cases were not under my own immediate treatment.

I can find comparatively few references to this complication in medical literature. Erichsen" says: "Hæmorrhage from the urethra may occur as the result of chordee and consequent rupture of some blood-vessels of the corpus spongiosum, as the consequence of attempts at passing the catheter, or as a simple oozing from the inflamed mucous membrane." White and Martin ${ }^{2}$ mention the occurrence of hæmorrhage at the end of micturition in acute posterior urethritis. "The hæmorrhage may be very free and will pass back into the bladder and the patient will pass it mixed with the urine at the termination of the act." Again, ${ }^{3}$ "“ "Russian clap' is the name applied to gonorrhœea of a hyper-acute type with lymphangitis, obstinate chordee, and free bloody discharge. Bleeding is due to the rupture of the intensely congested vessels of the urethral mucous membrane and both the pus and the semen are tinged with blood." Güterbock ${ }^{4}$ describes the occurrence of this complication under the name of black or Russian gonorrhoea. Taylor ${ }^{\overline{5}}$ recommends the localisation of the source of the hromorrhage by means of the urethroscope. Lydston ${ }^{6}$ mentions the bleeding occurring in association with severe chordee. Grünfeld ${ }^{7}$ mentions the case of a patient suffering from gleet and passing blood from the arethra who was examined with the urethroscope and a polypus being discovered it was removed by the snare.

It is evident, therefore, that bleeding may occur either in the acute or in the chronic stage of gonorrhoea; in the acute stage with severe chordee or with a posterior urethritis. This is rarely profuse, generally a mere tinging of the discharge, and probably will not call for any special treatment; it would be most unwise to use the urethroscope. In the chronic stage the bleeding may be profuse or slight. Profuse hæmorrhage, as in the first two of my cases, may occur after any extra exertion or after coitus (as in Case 1) in patients who have passed through the acute stage but who still have a discharge from the urethra. The bleeding in the majority of these cases arises from a granular or papillary patch in the anterior urethra; it may be very profuse and may demand immediate treatment. Slight and repeated hæmorrhages may occur in patients suffering from a chronic gleet and may arise from urethral polypi, papillomata, ulcer, or granular patch. Possibly these cases are more common than is generally supposed; a patient may make the statement that he is passing blood in his urine and may conceal the fact that he has a chronic urethral discharge. When a specimen of the urine is examined it will be found to contain blood and the patient may be subjected to much unnecessary and fruitless examination of the bladder and kidneys. If care be taken it is quite easy to ascertain that the hæmorrhage comes from the urethra.

With regard to the treatment of these cases, in the acute stage the hæmorrhage in itself does not call for any special treatment and the case may be managed on ordinary lines. In the chronic stages, when the hæmorrhage is profuse Erichsen ${ }^{\gamma}$ recommends the application of ice or the introduction of a large gum-elastic catheter and pressure by means of a bandage to the penis and perineum, probably an exceedingly uncomfortable method of treatment. Rest in bed with elevation of the penis, ice to the perineum, and the use of a weak astringent injection such as sulpho-carbolate of zino may be successful. Undoubtedly the best results are obtained by the use of the urethroscope ; the source of the hæmorrhage may then be detected and the bleeding may be

1 The Science and Art of Surgery, vol. ii. p. 1167.

2 Genito-urinary Surgery, p. 101 3 Ibid., p. 96 .

4 Die Krankheiten der Hainrohre und der Prostata.

5 Genito-urinary and Venereal Disease, p. 413. Ibid., p. 129. Der Harnrihrenspiegel, Wiener Klinik, 1877, pp. 94 and 95 controlled by direct applications under the guidance of the eye to the diseased area. This was the treatment adopted in two of my cases and it was eminently satisfactory. The tube is introduced into the urethra and the blood is removed with fragments of wool in holders; the urethra is then inflated with air and this in itself tends to check the hæmorrhage, the light is applied, and the urethra is inspected. Blood may then be seen issuing from the diseased area. The tube is passed down to this area, the urethra is deflated, and a frag. ment of wool dipped in a solution of perchloride of iron is applied to the whole of the bleeding surface. Other solutions may be used in preference to the iron, such as tineture of hammamelis, adrenalin, \&c.

The effect of this treatment is to increase the amount and purvleney of the discharge. This may be controlled by the use of an injection of protargol and the occasional application of a 10 per cent. or a 20 per cent. solution of protargol to the diseased area through the urethroscope tube. If the gleet is due solely to this patch of disease, and not to a posterior urethritis, chronic vesiculitis, or prostatitis, it will be readily cured by this method. If a polypus is, or if papillomata are, the cause of the diseharge and hæmorrhage such conditions can be satisfactorily diagnosed and treated only by means of the urethroscope.

I wish to thank Mr. W. H. Brown and Mr. A. Wr. Mayo Robson, in whose admission wards these cases were seen, for permission to publish them.

Leeds.

\section{REMARKS ON CERTAIN METHODS OF PHYSICAL DIAGNOSIS IN DISEASES OF THE CHEST.} WITH ILLUSTRATIVE CASES.

By A. G. AULD, M.D. GLASG., M.R.C.P. LOND,

EATE ASSISTANT PHYSICIAN TO THE GLASGOW BOYAL INFIRMARY ; HONORARY PHYSICIAN TO THE WESTMINSTER GENERAL DISPENSALI.

IN considering the various diseases to which the lungs are subject, a general law as to their distribution is found to operate. It is found that lesions of a tuberculous nature usually attack the apices, whereas most other diseases cominonly attack the bases. In reference to the latter it is only necessary to mention such common affections as bronchitis, the various forms of pneumonia, and pleurisy. It is especially necessary to bear this in mind in the case of bronchial affections and the lesions of the pulmonary parenchyma which may complicate them. Just as in tuberculosis the examiner's attention is instinctively, so to speak, directed to the apices, so in non-tuberculous affections it should contrariwise be directed to the bases. No doubt the entire chest ought to be thoroughly examined in every case of suspected disease within the thorax, but it is just in the simpler and commoner conditions - in which the examination is apt to be slipshod - that the bases should be examined with special care. Take, for instance, the case of a troublesome cough remaining after infuenza or acute bronchitis. Examination of the anterior part of the chest may be negative and possibly the examiner puts down the cough to some obscure irritation of the bronchi not amenable to auscultation. Now it is very likely that in one or other base, and possibly very low down, an area, which may be quite small, is the seat of numerous bronchitic râles. It is less frequent than is usually supposed that a cough exists the cause of which eludes physical examination.

If, then, the importance of examining the pulmonary bases be so manifest it is necessary that full use be made of all the means which assist in rendering the examination complete. Now, in addition to the usual methods of percussion, auscultation, \&c., we have at our disposal others which are both simple and reliable. Two at least of these are applicable in all cases of chest disease, yielding as they always do positive data which materially assist both diagnosis and prognosis. The methods to which I refer are, however, more particularly concerned with the pulmonary bases and so their practical application may shortly be considered in that connexion.

Technique of the Physical Examisation.

It is best first of all to determine the condition of the organs immediately underlying the diaphragm, ascertaining 